\title{
El reto de la digitalización del archivo sonoro en los servicios públicos de radiodifusión. El caso de Catalunya Ràdio
}

\author{
Por Montse Bonet y David Fernández Quijada
}

Resumen: Primera aproximación a las implicaciones de la digitalización en el archivo sonoro de una emisora de radio a partir del estudio de caso de la cadena pública Catalunya Ràdio. Más allá de la indudable importancia del equipamiento técnico, el software o los estándares de compresión, almacenamiento e indexación, la conversión de un archivo sonoro a código binario tiene otras implicaciones que, de forma breve, repasamos aquí. Los ejes centrales de este proceso podrían resumirse en: cambios en los perfiles profesionales y en las rutinas productivas, integración de lenguajes y posible universalización del fondo documental.

Palabras clave: Digitalización, Radio, Catalunya Ràdio, Archivo sonoro, Rutinas productivas, Perfiles profesionales.

\section{Title: The challenge of the digitisation of public service broadcasters' audio archives. A case study of Catalunya Rà- dio}

Abstract: This paper offers an approach to the implications of digitising a radio station's audio archive, based on a case study of the public broadcaster Catalunya Ràdio. Beyond the unquestionable importance of factors such as technical equipment, software or standards of compression, and storage and indexing, the conversion of an audio file into binary code has other implications that are briefly reviewed. The essential parts of this process can be summarised as follows: changes in professional profiles and production routines, the integration of languages, and the possible universality of documentary resources.

Keywords: Digitisation, Radio broadcast, Catalunya Ràdio, Audio archive, Production routines, Professional profiles.

Bonet, Montse; Fernández Quijada, David. «El reto de la digitalización del archivo sonoro en los servicios públicos de radiodifusión. El caso de Catalunya Ràdio». En: El profesional de la información, 2006, septiembre-octubre, v. 15, n. 5, pp. 390-396.

\section{Contexto de la digitalización de la radio en España}

DURANTE MUCHOS AÑOS LA RADIO ESPAÑOLA soslayó la renovación tecnológica, especialmente en materia de equipamiento. En aquellos momentos la limitación temporal a diez años de la concesión administrativa se convirtió en la excusa esgrimida para no invertir en nuevos equipos, ignorándose la estrategia a largo plazo.

Sin embargo, en la década de los 80 y los 90 , iniciada ya la etapa democrática, renovadas casi automáticamente las concesiones y ante el aumento de la competencia por la multiplicación de medios, la radio española no pudo evitar por más tiempo una renovación que era ya una exigencia sin paliativos, consciente además de que no podía seguir ofreciendo una calidad de sonido inferior a la que toda persona con unos ingresos económicos medios podía tener en su casa con los equipos domésticos. En esos años, por otro lado, la tecnología adquirió protagonismo, convirtiéndose en herramienta imprescindible para unas emisoras que perseguían la ra- cionalización en la gestión y la máxima rentabilidad económica ante la necesidad de afrontar la nueva situación concurrencial.

Unas antes que otras, rápidamente o más lentamente, lo cierto es que la industria radiofónica española se vio obligada finalmente a subir al tren de la tecnología. El máximo exponente tecnológico de la radio de los 90, y su gran objetivo, fue sin duda la digitalización y que ésta implicara a todo el proceso, desde la captación de la señal hasta su recepción, pasando por la emisión y el tratamiento, junto con el uso del satélite. Para las emisoras 


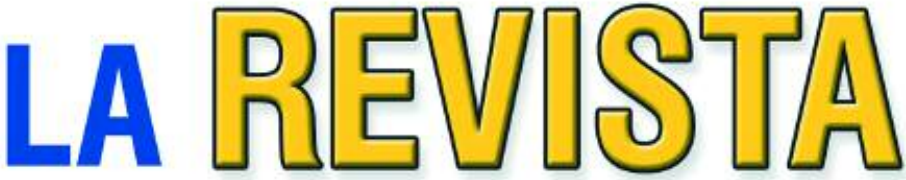 \\ DEL MUNDO DE LAS BIBLIOTECAS}

\section{Biblioteca}

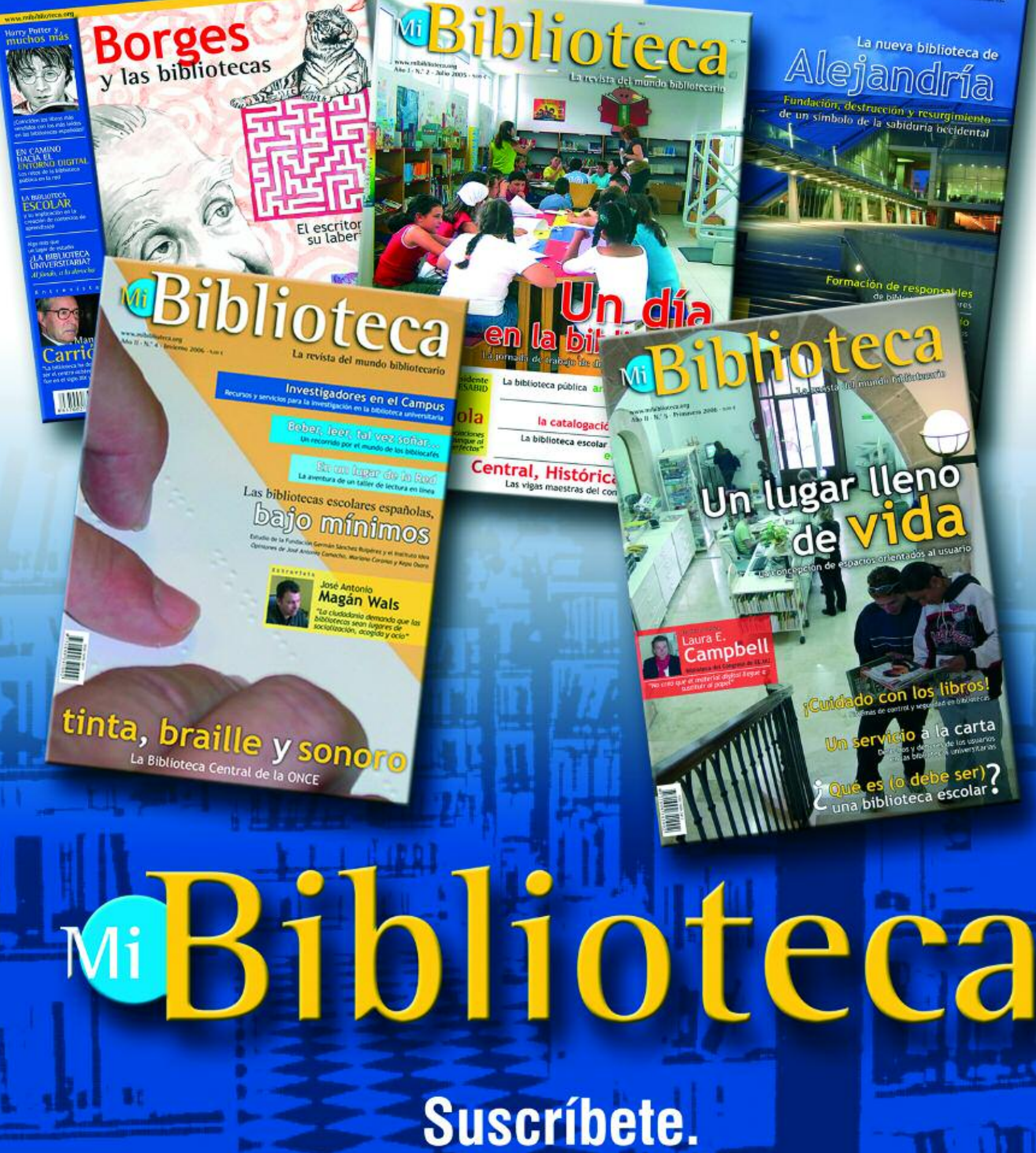

\section{Biblioteca}


históricas supuso un proceso lento y muy caro, a diferencia de las que nacieron nuevas a partir de mediados de la década, ya que éstas optaron, inteligentemente, por nacer "digitales" (Bonet, 1995). Conviene recordar que durante mucho tiempo, e incluso ahora en algún caso, este proceso en la radio ha sido exitoso en alguna de sus fases pero deja mucho que desear en otras. Véase, sino, el nivel de estancamiento de la emisión digital bajo el estándar europeo Eureka-147, conocido como dab (digital audio broadcasting). Igualmente, durante mucho tiempo han convivido en las redacciones las máquinas analógicas y las digitales. Son ejemplos de tal convivencia (que podía suponer doblar el esfuerzo productivo) el uso contemporáneo de grabadoras de casete y minidisc; o bien los primeros ordenadores con software de edición de sonido que no estaban conectados en red.

Otro de los motivos por los cuales la digitalización exige un lugar preeminente en el proceso productivo radiofónico, más allá de la calidad sonora que se quisiera ofrecer a la audiencia, tiene su origen en las propias exigencias derivadas de la implantación y desarrollo de la sociedad de la información. La sociedad en red es la que en sus modos de producción cambia sus activos materiales o de capital por otros intangibles; es la que se aprovecha de la universalización tecnológica (y por ello no sólo las grandes empresas tienen ahora acceso a las tecnologías de captura, gestión, organización y difusión de información en grandes cantidades); es aquella cuyas empresas tienden hacia la empresa red, empresa virtual u organización virtual, basada más en alianzas estratégicas y en outsourcing. Como indica Alfons Cornella (1999, p. 4), "la diferencia en esta sociedad informacional emergente es que entramos ahora en una forma específica de organización social en la que la generación, proceso y transmisión de información se convierten en las principales fuentes de productividad y poder". En suma, la sociedad del conocimiento convierte la información en materia prima y la genera, la intercambia y pone en circulación de forma cada vez más acelerada y acumulativa.

Como industria cultural, la radio puede aplicar todo su know-how sobre la producción, gestión y difusión de contenidos intangibles de valor simbólico, pero para ello precisa adaptar previamente su cadena productiva al código binario. A medio y largo plazo, sin embargo, este proceso puede conllevar consecuencias de gran alcance que de momento se hallan tan sólo en estado embrionario. Como veremos a continuación, la digitalización está conduciendo al rediseño de los perfiles profesionales y la reestructuración de las rutinas productivas. Esto ya sucedió en épocas anteriores, como por ejemplo con la introducción de los estudios autocontrol o la aparición de los periodistas radiofónicos, tras cuarenta años de sequía informativa bajo la dictadura.

\section{«En el actual contexto de cambio tecnológico profundo, los profesionales de la documentación, gestores de información especializados, adquieren un nuevo protagonismo»}

De todas maneras, en ningún caso se había manifestado un tercer elemento que ahora sí debemos considerar, la multimedialidad: la digitalización integra lenguajes y los reduce a ceros y unos, sea cual sea o hubiera sido su medio, soporte físico o equipamiento de referencia (televisión, radio, prensa, cine, etc.). Por el momento solamente podemos preguntarnos si tal integración puede conducir al medio radiofónico, con el tiempo y la competencia, a redefinirse como medio de comunicación de masas: "La reciente convergencia de las capacidades de las TIC con las de la radio y la televisión nos hace comprender que nuestra premiada producción editorial (clips de vídeo, entrevistas de audio, transcripciones, etc.) puede ser entendida como una serie de activos digitales, que pueden ser identificados, intercambiados y distribuidos utilizando una infraestructura digital avanzada. Se nos ofrece una oportunidad tremenda de importancia cultural y eficacia operativa" (White, et al, 2003).

\section{Rutinas de producción y perfiles profesionales}

Superados los primeros problemas de implantación y desarrollo, la digitalización está suponiendo una modificación clara de las rutinas productivas, aunque su alcance real esté todavía por determinar dado el estadio aún inicial del proceso. Algunas de estas transformaciones son las siguientes:

- Con el equipamiento digital de captación de sonido (p. e., minidisc) se facilita el trabajo del periodista en su labor de selección de los fragmentos de audio;

- se dispone de mayor facilidad para buscar información y contrastarla,

-teóricamente, pues, la información elaborada y ofrecida debería ser más profunda, contextualizada y trabajada, ya se trate de una emisora de programación generalista o una radiofórmula informativa o musical;

- se tiene más control del propio producto ya que se puede grabar la propia voz o entrevistas y montar noticias, reportajes, fragmentos musicales, etc., sin la asistencia de un técnico;

- el trabajo queda, en cierta forma, más "socializado" puesto que una vez elaborado se almacena en un servidor de manera que pueda ser recuperado por cualquier otro profesional;

- con el equipamiento digital de almacenamiento de datos, un tra- 
bajador (incluso en administración, publicidad o marketing) tiene a su alcance, sin moverse de su puesto de trabajo, bases de datos y repositorios que hace sólo unos años eran impensables o implicaban un desplazamiento físico e incluso, en algunos casos, un permiso especial de acceso.

En consecuencia, el proceso de elaboración queda libre de intermediarios totalmente o en parte, lo cual obliga al replanteamiento de algunos perfiles profesionales, entre ellos los del equipo técnico, pero igualmente el del periodista o profesional de la comunicación en genérico. Curiosamente esta linealidad o continuidad sobre el propio producto, que en anteriores etapas podía verse roto por la intervención de otros profesionales, contrasta con la discontinuidad facilitada por la edición no lineal en el sistema digital.

En este contexto de cambio tecnológico profundo adquiere un nuevo protagonismo el papel jugado por los profesionales de la documentación, gestores de información especializados, cuyo perfil profesional ha incorporado también en los últimos años nuevas habilidades y nuevos conocimientos. Como apunta Haefner (2000, p. 13): "tenemos que cambiar nuestra mentalidad archivística. Es principalmente la información y no su soporte lo que debemos preservar". En el mundo de la comunicación, saber gestionar fuentes es básico y una parte del éxito profesional se basa en ello. Nos referimos, por supuesto, a saber a qué fuentes (personas, instituciones, etc.) recurrir para obtener información, entenderla mejor o contextualizarla. Sin embargo, los flujos de entrada y salida de datos son actualmente de tal volumen que se necesita el esfuerzo conjunto de las redacciones y el departamento de documentación.

En un tanto por ciento elevado, el origen de los buenos trabajos radiofónicos suele ser una buena documentación, lo cual redunda en beneficio del archivo sonoro, que ve así enriquecido su fondo con nuevo material elaborado por periodistas y comunicadores en general. "Mientras los radiodifusores se mueven hacia un workflow completamente digitalizado, que comprende la producción, la difusión y el archivo, sigue creciendo la demanda de acceso fácil a los archivos digitales con fines de investigación o reutilización del contenido de audio. (...) Además, el archivo de audio de un gran radiodifusor refleja la evolución de sus contenidos a lo largo del tiempo y como tal cumple con la importante función de repositorio como parte de una memoria cultural común" (Larson; Beckers; Schlögell, 2005).

\section{Caso de estudio: Catalunya Ràdio'}

\section{Orígenes y evolución del sistema de documentación}

Desde el nacimiento de la emisora se vio claro que había que contar con un departamento de documentación que diera respuesta a las necesidades productivas de la nueva compañía. Como en toda empresa periodística, debía ser complementado, además, con una fonoteca que se encargara de conservar y catalogar el recurso que es propio en la empresa radiofónica: el sonido. Para el archivo de prensa el servicio de documentación de Catalunya Ràdio utiliza el programa Excalibur, que genera una indexación automática de artículos a través del reconocimiento óptico de caracteres, una función completada por el equipo de documentalistas de la casa. Este programa ha sustituido al tradicional servicio de dossiers de prensa (Miralles; Vizcaya, 2002) y ha permitido unificar el trabajo del equipo de documentación de Catalunya Ràdio y el de Televisió de Catalunya, la empresa de televisión pública propiedad de la Generalitat de Catalunya.

El archivo sonoro está dividido en dos secciones. Por un lado, en la fonoteca están los cortes de voz. Funciona con el sistema de base de datos documental Airs, que utiliza tanto campos de lenguaje natural como controlado. Desde el Departamento de Informativos se hace una primera selección de los cortes de voz susceptibles de conservarse, guardados en el editor de sonido Dalet, es decir, ya digitalizados. Posteriormente llegan hasta el documentalista que, aplicando criterios propios de su oficio, es quien finalmente indiza e introduce los datos requeridos en la base de datos.

Otra parte del archivo sonoro es la discoteca, que comprende la música utilizada en las diversas programaciones, así como programas enteros de las cuatro cadenas ${ }^{2}$, incluidos los conciertos que graba la propia emisora (por ejemplo, los de música clásica de Catalunya Músi$c a$, que acaban siendo editados en cd, una vez obtenido el master). Como es obvio, el proceso de digitalización hará que sea innecesario distinguir entre discoteca y fonoteca. Finalmente está el paralelo de antena, es decir, la grabación de todo lo que se emite.

\section{«En el entorno completamente digital y reticular hacia el que inevitablemente se dirige la radio, la existencia de un archivo sonoro puede parecer algo artificial, ya que todo tipo de archivo se reduce a código binario»}

El almacenaje permanente se realiza en un disco magneto-óptico, con una capacidad de 2,6 GB o el equivalente a 24 horas estéreo de sonido con calidad de emisión. El soporte magneto-óptico representa una mejora notable en calidad sobre los soportes de bobina abierta empleados anteriormente y además ahorra espacio físico. Otros soportes que se habían utilizado antiguamente eran las cintas de vídeo U-Matic y Betamax digital. Aunque parezca paradójico, la utilización de la banda de audio de las cin- 
tas de vídeo como soporte de almacenamiento tiene una larga tradición en el entorno radiofónico, debido a su alta calidad respecto a los soportes analógicos coetáneos y a que permitían una mayor duración de las grabaciones.

\section{La necesaria adaptación técnica}

La memoria histórica actual se basa en ceros y unos. El código binario se ha convertido en el estándar de facto para los sistemas de almacenaje de audio, más allá de la relación tradicional entre el formato y el soporte específico. Esta relación se había mantenido con los primeros formatos digitales, como el dat o el cd, pero la tendencia al almacenaje de archivos en formato de datos ha roto esta tradición. Las dos razones de base que están detrás de esta elección de formatos de archivo de datos en lugar de formatos de audio propios son:

- un previsible menor nivel de obsolescencia a medio y largo plazo, y

- la integración que se deriva de esta elección facilita la consulta de datos dentro y fuera de la empresa puesto que no es necesario disponer de un aparato concreto para reproducir cada formato. Un terminal de ordenador es suficiente y permite, incluso, el trabajo a distancia desde casa o el propio lugar de la noticia.

Ante el avance espectacular de la informática y las telecomunicaciones, sigue vigente la necesidad de conservar no sólo el hardware necesario para la reproducción, tal como ocurría con los soportes analógicos, sino también un software que permita la lectura de los formatos conservados, lo que de hecho supone, en el entorno digital, mayores exigencias para la reproducción futura del material conservado. De ahí la necesidad de decidir el formato de almacenaje. Organismos internacionales especializados como la $I A$ SA (International Association of Sound and Audiovisual Archives) recomiendan un formato sin com- presión a máxima calidad, aunque ni tan siquiera los propios miembros de la institución cumplen siempre este requisito (Spence, 2002). En el caso de Catalunya Ràdio se ha optado por un formato de compresión con calidad, atendiendo a los propios criterios de la compañía. Concretamente se emplea el formato $M P 2$ con una frecuencia de muestreo de $48 \mathrm{KHz}$ con dos niveles de bit-rate: 256Kbps estéreo y $128 \mathrm{Kbps}$ mono. Este material se sirve tanto en streaming (el usuario lo va escuchando mientras lo está recibiendo) como en descarga para su consulta posterior.

El archivo actual de discoteca comprende unas 100.000 horas aproximadamente que, con el estándar de compresión elegido vienen a representar unos 10TB de volumen en disco duro. A ello se han de añadir unas 20.000 horas de fonoteca, unos $2 \mathrm{~TB}$ adicionales. Las previsiones que maneja la compañía se mueven en un incremento de 500GB anuales de volumen para discoteca y unos 230GB para fonoteca. Todo el material almacenado se replica periódicamente en un robot, con un brazo mecánico articulado, un almacén interno de cintas, lectores-grabadores y una aplicación de gestión. Se trata de un sistema cerrado que utiliza cintas y formatos de grabación internos, no válidos para el intercambio.

Ambos archivos, además, están a disposición de las delegaciones que, a través de una red rdsi dedicada de $2 \mathrm{Mbps}$, permite que tanto éstas como la cabecera (en Barcelona) compartan exactamente los mismos materiales sin importar su ubicación o peso específico dentro la cadena.

El descenso en los precios del hardware $\mathrm{y}$, especialmente, de los discos duros, ha permitido dejar en un segundo plano el problema del coste y afrontar con realismo la necesidad de casar la capacidad disponible en cada momento con la conservación de los archivos de audio con la calidad requerida.
En definitiva podríamos decir que el proceso de digitalización que afronta Catalunya Ràdio cumple con los motivos esgrimidos por Spence (2002):

-Inminente obsolescencia de la tecnología analógica.

-Preservación de la información conservada.

- Medio de almacenaje estable.

-Recuperación más fácil y rápida.

-Aumento en los niveles de acceso.

- Mayor seguridad.

-Ahorros económico y de espacio en el almacenaje.

- Generación de ingresos adicionales.

\section{De un archivo sonoro a uno multimedia}

En el entorno completamente digital y reticular hacia el que inevitablemente se dirige la radio, la existencia de un archivo sonoro puede parecer algo artificial, ya que todo tipo de archivos se reduce a código binario. El de Catalunya Ràdio está en pleno proceso de transformación, pasando con bastante rapidez de un archivo puramente sonoro a uno multimedia que, además, debe culminar con su integración con el archivo de Televisió de Catalunya, un proyecto en el que ya se está trabajando desde los servicios técnicos. En palabras de Jordi Rueda, director de explotación y recursos de la empresa, esta unificación contempla tres dimensiones:

- Herramientas: de cara al usuario integración de los diferentes tipos de aplicaciones utilizadas en los procesos de búsqueda, almacenaje, producción y difusión.

-Programas: unificar los diferentes fondos de archivos (música, imágenes, textos), ahora divididos según criterios periodísticos entre informativos, deportes y programas.

-Empresarial: creación de un sistema global de indexación y almacenaje para toda la Corporació Catalana de Ràdio i Televisió (Ccrtv), compartiendo recursos 


\section{Soluciones \\ de Gestión documental y e-contenidos}

Sistemas de Gestión documental.

Digitalización.

Gestión de Archivos.

Parametrización de Interfaces Millenium, Absys. Desarrollo de Opac-web.

Portales y Webs accesibles (AAA)

Publicaciones Digitales.

Productos Multimedia.

Catalogación y procesamiento de información.

Derechos de autor en entorno digital.

Posicionamiento y e-Marketing.

Creación y Mantenimiento de contenidos digitales.

Outsourcing.

Desarrollo Multilingües y Multiformatos en soportes online, offline y plataformas móviles.

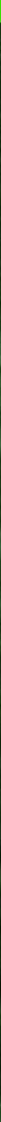


que gracias a la digitalización se convierten en comunes.

La primera fase de este proyecto, ahora en marcha, prevé la integración de los archivos de informativos de Catalunya Ràdio y de Televisió de Catalunya. Manteniendo siempre la seguridad del sistema como un criterio central, se pretende crear un gestor de base de datos capaz de trabajar con los diferentes sistemas que actualmente se utilizan en radio y televisión y que en el caso de la radio han de conducir a la sustitución del Airs por un software elaborado desde los propios servicios técnicos de la Ccrtv, Digition. Esta integración ya es visible en el entorno web con presencia conjunta de ambos servicios informativos, gestionada por una redacción especializada ubicada en la sede de la Ccrtvi, el brazo interactivo de la Crrtv.

Lejos de verse como una amenaza por el poder que la imagen ha alcanzado en la sociedad contemporánea, "el apoyo de textos, de imágenes e incluso de imágenes en movimiento refuerza la comunicación de la radio", en palabras de Rueda. Ello resulta especialmente interesante si tenemos en cuenta que, en el contexto de la digitalización, una de las características que adquiere la señal radiofónica es la posibilidad de enviar diferentes tipos de lenguajes a los nuevos displays que incorporan los receptores radiofónicos. "Se puede interpretar esto como una especie de convergencia mediática entre la radio, la televisión, el cine y el texto que conduce a un resultado que podría llamarse archivos multimedia" (Haefner, 2000, p. 14).

El software con el que se trabaja en las redacciones digitales ya está adaptado a estas nuevas necesidades. Así, el sistema Dalet Plus, versión actualizada del programa utilizado para el tratamiento del sonido, posee la capacidad de incorporar metadatos que leídos desde el software de automatización con el que la Ccrtvi programa los contenidos de la web, permite sincronizar imágenes concretas a cada archivo sonoro.

\section{Conclusiones}

En el entorno radiofónico, la digitalización supone algo más que una mera cuestión técnica circunscrita a los equipos y las ondas electromagnéticas. La conversión a código binario obliga a un rediseño de los perfiles profesionales y a una reestructuración de las rutinas productivas, no sólo de la profesión periodística sino también de otros departamentos clave como los de publicidad, administración y, por supuesto, documentación. Falta todavía por ver de qué forma van encajando estas transformaciones, pues los cambios se suceden rápidamente y la realidad va dibujándose a medida que la propia tecnología progresa y mejora. La gestión de estas tensiones supone uno de los principales retos a los que se ven sometidos los operadores de sectores que, incluidos en el campo de las industrias culturales, utilizan la información como materia prima de su trabajo.

Catalunya Ràdio inició su particular travesía digital en los años 90. Actualmente, ya asumidas e integradas las exigencias derivadas de esta digitalización, consciente de que una vez iniciado el proceso no puede pararse, aparece en buena disposición para dar un paso adelante con la conversión de su archivo sonoro en multimedia. Esto tiene implicaciones empresariales y de gestión pero, por encima de todo, pone de manifiesto la voluntad de la radio pública de convertirse en un motor de los servicios de la sociedad de la información, actuando como ejemplo para otros operadores.

Como parte de su función de radio pública, Catalunya Ràdio está construyendo un archivo que se configura como parte importante de la memoria histórica del país. Ello supone una serie de responsabilidades importantes, desde su efectiva conservación con las máximas condiciones de seguridad hasta la posi- ble consulta de ese archivo por parte de la ciudadanía.

\section{Notas}

1. Buena parte de la información técnica y de funcionamiento del archivo sonoro de la emisora se ha extraído de una entrevista realizada a Jordi Rueda, director de explotación y recursos, realizada el día 22 de mayo de 2006 en $\mathrm{Ca}$ talunya Ràdio. Los autores desean agradecer su atención y la colaboración del personal técnico y de documentación de la cadena para la elaboración de este artículo.

2. Catalunya Ràdio, Catalunya Música, Catalunya Informació e iCat (antes Catalunya Cultura).

\section{Bibliografía}

Bonet, Montse. La ràdio espanyola en el context dels grups de comunicació: evolució de la indústria radiofònica 1924-1994, [tesis doctoral]. Bellaterra: UAB, Departament de Comunicació Audiovisual i Publicitat, 1995, ISBN 84-490-0532-9.

Haefner, Albrecht. "Renaissance in archiving: the present upheaval in audiovisual archives: evolution towards multimedia archiving?". En: SASA National conference, 2000.

Larson, Martha; Beckers, Thomas; Schlögell, Volker. «Structuring and indexing digital archives of radio broadcasters». En: Workshop digitale medianarchive at the 25. Tagung der Gesellschaft für Informatik. Consultado en: 20-05-06.

http://www.imk.fhg.de/sixcms/media.php/130/gi2 005_wdrprojekt.pdf

Miralles, Teresa; Vizcaya, Raquel. "El Departament de Documentació de Catalunya Ràdio". En: Item, 2002, n. 32, pp. 51-55.

Schüller, Dietrich (ed.). The safeguarding of the audio heritage: ethics, principles and preservation strategy, International Association of Sound and Audiovisual Archives Technical Committee. Consultado en: 28-05-06. http://www.iasa-web.org/iasa0013.htm

Spence, John. Dams \& digitization preparedness. En: IASA journal. Consultado en: 25-05-06.

http://www.iasa-web.org/journal_articles/spenc e_john.pdf

White, Alison M., et al. «PB Core. The public broadcasting metadata initiative: progress report». En: Dublin core conference (DC-2003): supporting communities of discourse and practice-metadata research \& applications, 2003. Consultado en: 15-05-06.

http://www.ischool.washington.edu/dc2003/

Montse Bonet y David Fernández

Quijada, Dept. de Comunicació Audiovisual i Publicitat, Fac. de Ciències de la Comunicació, Univ. Autònoma de Barcelona. Edif. I.

08193 Bellaterra.

Tel.: +34-935811543

montserrat.bonet@uab.es

Tel.: +34-935814782

david.fernandez@uab.es 